\title{
Evaluation of Bioactivities and Phenolic Content of Selected Edible Mushrooms in Malaysia
}

\author{
Fai-Chu Wong ${ }^{1,2}$, Tsun-Thai Chai ${ }^{1,2}$, Soon-Leong Tan ${ }^{2}$ and Ann-Li Yong ${ }^{2}$ \\ ${ }^{1}$ Centre for Biodiversity Research, ${ }^{2}$ Department of Chemical Science, Faculty of Science, Universiti Tunku Abdul Rahman, \\ 31900 Kampar, Malaysia
}

*For correspondence: Email: wongfc@utar.edu.my; Tel: +605-468 8888 ext 4521; Fax: +605-4661676

Received: 13 August 2012

Revised accepted: 15 October 2013

\begin{abstract}
Purpose: To determine the radical scavenging, metal chelating, antibacterial and cytotoxic activities of five edible mushrooms in Malaysia.

Methods: Mushrooms (H. tessulatus, $P$. eryngii, $P$. florida, A. polytricha and $F$. velutipes) were ovendried and extracted with $90 \%$ ethanol. Radical scavenging and metal chelating assays were based on the measurement of 1,1-diphenyl-2-picrylhydrazyl (DPPH) and ferrozine absorbance at 517 and 562 $n m$, respectively. Mushrooms total phenolic and flavonoid contents were determined by spectrophotometric methods. Antimicrobial activity was measured using Kirby-Bauer Susceptibility Test. Cytotoxicity was assessed using brine shrimp toxicity assay.

Results: Total phenolic and flavonoid contents ranged from 0.90 - $6.03 \mathrm{mg}$ GAE per $\mathrm{g}$ of dry sample and $0.17-6.95 \mathrm{mg} Q E$ per $g$ of dry sample, respectively. A. polytricha demonstrated the strongest radical scavenging and metal chelating activities. Moderate antimicrobial activity was found for extracts of both P. florida and A. polytricha. Cytotoxicity $L D_{50}$ ranged from $46.9-115.8 \mu \mathrm{g} / \mathrm{ml}$.

Conclusion: The results suggest that $A$. polytricha is a suitable candidate for chemoprevention and would safe for use in large doses.
\end{abstract}

Keywords: Cytotoxicity, Flavonoid, Free radical scavenging, Metal chelating, Mushroom, Phenolic

Tropical Journal of Pharmaceutical Research is indexed by Science Citation Index (SciSearch), Scopus, International Pharmaceutical Abstract, Chemical Abstracts, Embase, Index Copernicus, EBSCO, African Index Medicus, JournalSeek, Journal Citation Reports/Science Edition, Directory of Open Access Journals (DOAJ), African Journal Online, Bioline International, Open-J-Gate and Pharmacy Abstracts

\section{INTRODUCTION}

Since ancient times, mushrooms have been consumed by people from all over the world, for both their nutritional and culinary values. With their high protein, and, low fat and cholesterol contents, mushrooms are considered by many to be an ideal source of nutritional ingredients, rich in minerals, polysaccharides and polyphenols [1]. Some mushroom-derived polyphenolic compounds have been found to be powerful antioxidants , with potent free radical scavenging and metal-chelating activities [2].
Modern scientific research often provides consistent support for ethnomedicine. For instance, a ubiquitin-like protease isolated from the fruiting bodies of Calvatia caelata, as well as lectine extracted from edible Agaricus bisporus, were found to exhibit cytostatic activity against tumor cells [3]. More concrete evidence have been provided by clinical trials using extracts of Grifola frondosa [4], as well as polysaccharides isolated from Ganoderma lucidum [5] and Trametes versicolor [6]. Treatment groups given extracts from the aforementioned medicinal mushrooms were found to demonstrate decreased expression of tumor markers [4], increased natural killer (NK) cells activities [5] 
and higher survival rate [6], compared to control groups. Following successful clinical trials, polysaccharide isolated from $T$. versicolor had further been approved in Japan and marketed as an anti-tumor drug known as Kristin (PSK).

The worldwide emergence of multi-resistant bacteria strains is driving an urgent need in the search for novel antibacterial compounds. As a result of mushrooms' natural living environment (life cycles which depend on degrading dead organic matters) and the need to defend against pathogenic organisms in their environment, it is believed that potent antimicrobial compounds could potentially be extracted from mushrooms [7]. This prospect is supported by a previously reported case whereby antimicrobial farnesyl hydroquinones (Ganomycin $A$ and $B$ ) isolated from Ganoderma pfeifferi was found to inhibit the growth of methicillin-resistant Staphylococcus aureus [8].

In this paper, we tested and compared edible mushrooms in Malaysia for their radical scavenging, metal chelating and antibacterial activities. We focused on five mushrooms species that originated from four families, namely Hypsizygus tessulatus, Pleurotus eryngii, Pleurotus florida, Auricularia polytricha and Flammulina velutipes. Their corresponding levels of total phenolic and total flavonoid were also quantified and compared. Additionally, we assessed the mushrooms' cytotoxic activities in a brine shrimp assay. The aim was to contribute to the understanding of the antioxidant, cytotoxic and antibacterial potentials of different edible mushrooms, as well as potential application in chemoprevention.

\section{EXPERIMENTAL}

\section{Preparation of mushroom extracts}

Mushrooms ( $H$. tessulatus, $P$. eryngii, $P$. florida, $A$. polytricha and $F$. velutipes) were purchased from a local food store in Kampar, Malaysia in November and December of 2011. The mushroom identities were confirmed morphologically by referring to literature [9, 10]. The mushrooms were incubated in an oven at 40 ${ }^{\circ} \mathrm{C}$ for $48 \mathrm{~h}$ or until constant weight was observed. Each dried mushroom sample was then macerated for $24 \mathrm{~h}$ in $90 \%$ ethanol (1:10, $w / v)$ at room temperature. After removing the ethanol extract, maceration was repeated with fresh $90 \%$ ethanol. The extracts were combined and filtered, concentrated and dried under reduced pressure. The dry extract was stored at $-20{ }^{\circ} \mathrm{C}$ until tested.
Determination of 1,1-diphenyl-2-picrylhydrazyl (DPPH) radical scavenging activity

DPPH radical scavenging activity was assessed as described previously with modifications [11]. To $1 \mathrm{ml}$ of DPPH working solution, $50 \mu \mathrm{l}$ of extract was added. The mixture was left in the dark for $30 \mathrm{~min}$ before its absorbance spectrophotmetrically (GENESYS 20 spectrophotometer, Thermo Scientific) was read at 517 $\mathrm{nm}$. A blank was prepared for each sample in which the DPPH solution was replaced with ethanol. DPPH radical scavenging activity was calculated using Eq 1.

$$
\mathrm{DPPH}=\{(\mathrm{Ac}-\mathrm{As}) / \mathrm{Ac}\} 100
$$

where $A c$ is the absorbance of control reaction (without mushroom extract), and As is the absorbance in the presence of mushroom extract. Trolox was used as reference. Results are also presented as $\mathrm{EC}_{50}$ values, which represent concentration of extract required to scavenge $50 \%$ of DPPH radicals.

\section{Determination of metal chelating activity}

Metal chelating activity was assessed as described previously with modifications [12]. Briefly, a mixture of extract $(0.2 \mathrm{ml})$ and $0.1 \mathrm{mM}$ FeSO4 $(0.2 \mathrm{ml})$ was mix and incubated for $5 \mathrm{~min}$. Next, $0.25 \mathrm{mM}$ ferrozine $(0.4 \mathrm{ml})$ was added, and the mixture incubated at room temperature for 10 min. Absorbance of the mixture was then read at $562 \mathrm{~nm}$. Metal chelating activity (MCA) was calculated as in Eq 1.

$$
\mathrm{MCA}=\{(\mathrm{Ac}-\mathrm{As}) / \mathrm{Ac}\} 100
$$

where $A c$ is the absorbance of control reaction (without mushroom extract), and $A s$ is the absorbance in the presence of mushroom extract.

\section{Determination of total phenolic contents}

The concentrations of total phenolic in the extracts were determined using a Folin-Ciocalteu colorimetric assay, as described previously with modifications $[13,14]$. A mixture of extract $(0.1$ $\mathrm{ml}$ ) and $10 \% \mathrm{v} / \mathrm{v}$ Folin-Ciocalteu reagent $(0.2 \mathrm{ml})$ was first incubated at room temperature for 3 min. Next, $0.8 \mathrm{ml}$ of $700 \mathrm{mM} \mathrm{Na}_{2} \mathrm{CO}_{3}$ was added and the mixture was incubated at room temperature for $2 \mathrm{~h}$. Absorbance of the mixture was read at $765 \mathrm{~nm}$. A standard curve was prepared from 0 - $42 \mathrm{mg} / \mathrm{L}$ gallic acid. Total phenolic content was expressed in mg gallic acid equivalents/g dry matter. 


\section{Determination of total flavonoid contents}

The concentrations of total flavonoid in the extracts were determined as described previously [14]. Mushroom extract $(0.2 \mathrm{ml})$ was added to $0.15 \mathrm{ml}$ of $\mathrm{NaNO}_{2}$ and the mixture was incubated at room temperature for $6 \mathrm{~min}$. Next, $0.15 \mathrm{ml}$ of $\mathrm{AlCl}_{3} \cdot 6 \mathrm{H}_{2} \mathrm{O}(10 \% \mathrm{w} / \mathrm{v})$ was added to the mixture, which was then left at room temperature for $6 \mathrm{~min}$. Next, $0.8 \mathrm{ml}$ of $\mathrm{NaOH}$ $(10 \% \mathrm{w} / \mathrm{v})$ was added and the absorbance of the mixture was read at $510 \mathrm{~nm}$ after standing at room temperature for $15 \mathrm{~min}$. For the blank, the extracts were replaced with water. To correct for background absorbance, a blank was prepared for each sample in which the $\mathrm{AlCl}_{3} \cdot 6 \mathrm{H}_{2} \mathrm{O}$ was replaced with water. $A$ standard curve was prepared from $0-500 \mu \mathrm{g} / \mathrm{ml}$ quercetin dissolved in $80 \%$ ethanol. Total flavonoid content was expressed in $\mathrm{mg}$ quercetin equivalents/g dry matter.

\section{Kirby-Bauer antimicrobial susceptibility test}

The antibacterial activities of the selected mushrooms were tested using Kirby-Bauer disk diffusion method, against both Gram-positive (Staphylococcus aureus and Micrococcus luteus) and Gram-negative (Escherichia coli and Pseudomonas aeruginosa) bacterial strains. Briefly, bacterial culture inoculum was adjusted to $0.5 \mathrm{McF}$ arland standard and swapped onto the MHA agar. Sterile forceps were used to apply filter paper disks containing mushroom extracts onto the agar surface. Tetracycline antibiotic disks (Oxoid Ltd.) were used as positive control. MHA plates were incubated for $18-24 \mathrm{~h}$ at $37^{\circ} \mathrm{C}$, and diameter of the inhibition zone was measured (in $\mathrm{mm}$ ).

\section{Brine shrimp cytotoxicity assay}

To assess the toxicity of each extract, brine shrimp cytotoxicity assays were performed as previously described with modifications $[11,15]$. Eggs of brine shrimp (Artemia franciscana) originated from Great Salt Lake (USA) were purchased from Sera and mixed with artificial seawater (prepared by dissolving $38 \mathrm{~g}$ sea salt per liter of water). The eggs were allowed to hatch at room temperature for 48 to $72 \mathrm{~h}$. Larvae (nauplii) were attracted to one side of the vessel with a light source and collected with plastic pipette. To determine if the mushroom extracts were cytotoxic, different concentrations of each extract $(4000,2000,1000,500,200,100,50$ $\mu \mathrm{g} / \mathrm{ml}$ ) were tested, in triplicate. Ten brine shrimp larvae were then added to each vial containing the aforementioned extracts. After incubating for $24 \mathrm{~h}$ at room temperature, the numbers of dead and surviving brine shrimps were counted. LD $_{50}$ (dose required to kill $50 \%$ of the brine shrimps) was determined for each mushroom extract. Potassium dichromate was used as positive control.

\section{Statistical analysis}

Data were reported as mean \pm standard error of mean $(n=3)$. Statistical analysis was performed using SAS (version 9.2) and data analyzed using ANOVA. Differences between means were determined using Fisher's least significant difference test at the probability level of 0.05 .

\section{RESULTS}

\section{DPPH radical scavenging activity and $\mathrm{EC}_{50}$ values}

All the mushroom extracts exhibited DPPH radical scavenging activities in a concentrationdependent manner, in the range of 5 to $50 \mathrm{mg} / \mathrm{ml}$ (Figure 1). A. polytricha was found to have the highest DPPH scavenging activity (79 \%), followed by $P$. eryngii (52 \%) and $H$. tessulatus (43 \%), while $F$. velutipes and $P$. florida possessed $23 \%$, compared to a standard concentration of $50 \mathrm{mg} / \mathrm{ml}$ (Figure 1).

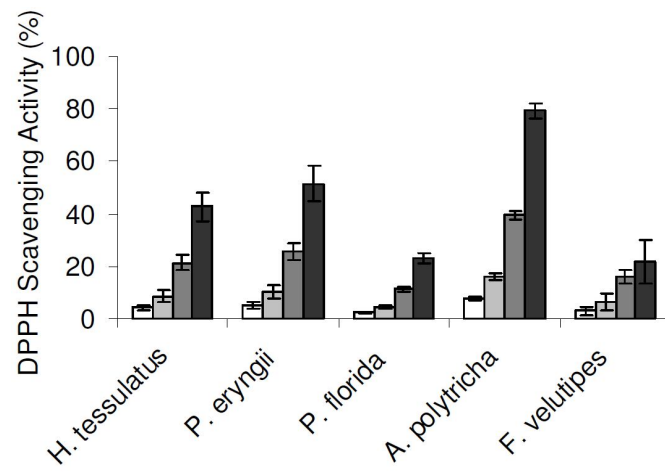

$\square 5 \mathrm{mg} / \mathrm{ml} \square 10 \mathrm{mg} / \mathrm{ml} \square 25 \mathrm{mg} / \mathrm{ml} \square 50 \mathrm{mg} / \mathrm{ml}$

Figure 1: DPPH radical scavenging activities of mushroom extracts at different concentrations. Data are reported as mean $\pm \operatorname{SE}(n=3)$

The corresponding $\mathrm{EC}_{50}$ values, which represent the concentration of extracts required to scavenge $50 \%$ of the DPPH radicals, were also determined. The mushrooms $\mathrm{EC}_{50}$ values (in $\mathrm{mg}$ dry matter per $\mathrm{ml}$ ) in descending order were $A$. polytricha $(31.58)>P$. eryngii $(48.53)>H$. tessulatus $(58.53)>F$. velutipes $(79.04)>P$. florida (109.30). The high antioxidation potentials of $A$. polytricha and $P$. eryngii were reflected by their low $E_{50}$ values ( $<50 \mathrm{mg}$ dry matter/ml), while $F$. velutipes and $P$. florida had $E_{50}$ values 
which were 2.5 and 3.5 folds higher, respectively, compared to that of $A$. polytricha.

\section{Metal chelating activity}

Chelating activities of the 5 mushroom extracts were also tested in a metal chelating assay. All the extracts showed metal chelating activities in a concentration-dependent manner, in the range from 5 to $50 \mathrm{mg} / \mathrm{ml}$ (Figures 2). At extract concentration $50 \mathrm{mg} / \mathrm{ml}$, A. polytricha showed the highest metal activities (100\%), followed by $F$. velutipes, $H$. tessulatus and $P$. florida (93.3, 90.4 and $89.1 \%$, respectively). The lowest activity was observed with $P$. eryngii (22.6\%), which was 4.4 folds lower compared to that of $A$. polytricha.

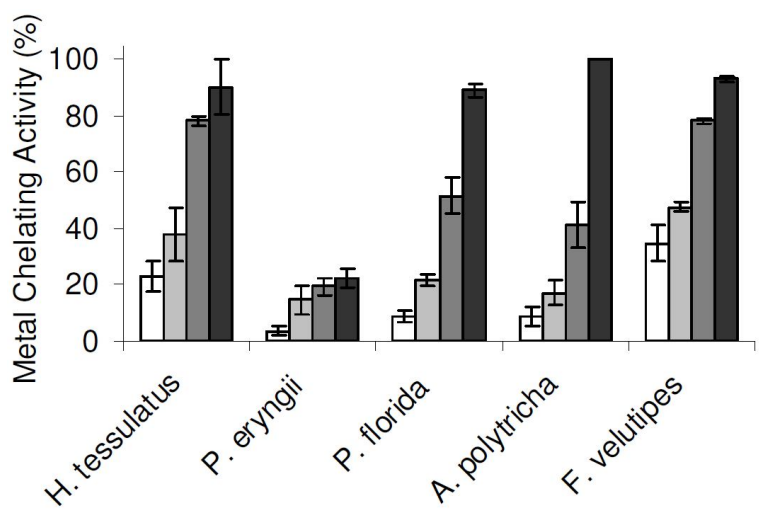

$\square 5 \mathrm{mg} / \mathrm{ml} \square 10 \mathrm{mg} / \mathrm{ml} \square 25 \mathrm{mg} / \mathrm{ml} \square 50 \mathrm{mg} / \mathrm{ml}$

Figure 2: Metal chelating activities of mushrooms extracts at different concentrations. Data are reported as mean $\pm \operatorname{SE}(n=3)$.

\section{Total phenolic and flavonoid contents}

As the antioxidation capacities of extracts were often linked to their levels of phenolic and flavonoid contents, we tested these mushroom extracts for their total phenolic and flavonoid levels. The highest level of total phenolic was detected in $A$. polytricha, followed by the groups of $P$. florida, $P$. eryngii and $H$. tessulatus which possessed moderate phenolic levels (3.14-3.72 mg GAE/g dry matter). The lowest level of total phenolic was detected in $F$. velutipes $(0.90 \mathrm{mg}$ $\mathrm{GAE} / \mathrm{g}$ dry matter). Consistently, the highest level of total flavonoid was detected in $A$. polytricha, and low level of total falconoid ( $<1 \mathrm{mg}$ $\mathrm{GAE} / \mathrm{g}$ dry matter) were detected in the other four mushrooms (Table 1). The lowest levels of phenolic and flavonoid were consistently detected in $F$. velutipes, which were 6.7- and 34.8-fold lower, respectively, when compared to the levels observed for $A$. polytricha.
Table 1: Total phenolic and flavonoid contents of five mushrooms

\begin{tabular}{lll}
\hline Mushroom & $\begin{array}{l}\text { Total } \\
\text { phenolics } \\
\text { (mg GAE/g } \\
\text { dry } \\
\text { matter) }\end{array}$ & $\begin{array}{l}\text { Total } \\
\text { flavonoids } \\
\text { (mg QE/g } \\
\text { dry } \\
\text { matter) }\end{array}$ \\
\hline Hypsizygus tessulatus
\end{tabular}

\section{Antibacterial activity}

Mushroom extracts were also tested for their antibacterial activities against both Grampositive ( $S$. aureus and M. luteus) and Gramnegative ( $E$. coli and $P$. aeruginosa) bacteria strains, using Kirby-Bauer disk-diffusion method. $H$. tessulatus, $P$. eryngii and $F$. velutipes exhibited minimal inhibition $(<10 \mathrm{~mm})$ against all bacterial strains tested (Figure 3). $P$. florida exhibited moderate inhibition (10 - $15 \mathrm{~mm})$ against both Gram-negative bacteria strains tested, while $A$. polytricha exhibited moderate inhibition against Gram-positive $S$. aureus and Gram-negative $P$. areruginosa.

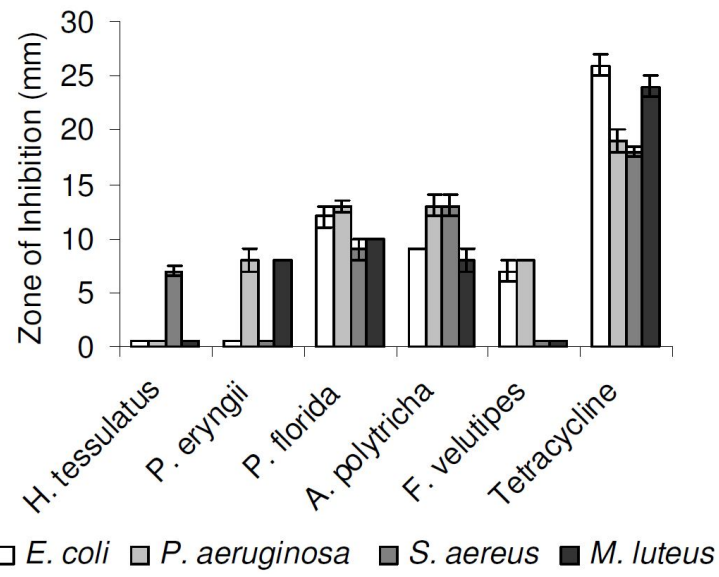

Figure 3: Antibacterial activities of mushroom extracts at different concentrations. Data are reported as mean $\pm \operatorname{SE}(n=3)$.

\section{Brine shrimp cytotoxic activity}

The mushroom extracts were tested in a brine shrimp assay to determine their cytotoxic activities. The results are reported as $\mathrm{LC}_{50}$ values, the extract concentrations required to kill $50 \%$ of a group of brine shrimps. Among the mushrooms tested, $H$. tessulatus was found to 
show the highest cytotoxic activity, with a $\mathrm{LC}_{50}$ of $46.9 \mu \mathrm{g} / \mathrm{ml}$ (Table 2). The cytotoxic activities for the mushrooms in descending order were $H$. tessulatus $>P$. florida $>P$. eryngii $>F$. velutipes $>$ A. polytricha (Table 2). Both A. polytricha $\left(\mathrm{LC}_{50}: 115.8 \mu \mathrm{g} / \mathrm{ml}\right)$ and $F$. velutipes $\left(\mathrm{LC}_{50}: 100.1\right.$ $\mu \mathrm{g} / \mathrm{ml}$ ) had cytotoxic activities which were 6.8and 5.8-fold lower, respectively, compared to potassium dichromate $\left(\mathrm{LC}_{50}: 17.0 \mathrm{\mu g} / \mathrm{ml}\right)$.

Table 2: Brine shrimp cytotoxicity of the mushrooms

\begin{tabular}{ll}
\hline Mushroom & $\begin{array}{l}\mathbf{L C}_{\mathbf{5 0}} \\
(\boldsymbol{\mu g} / \mathrm{ml})\end{array}$ \\
\hline Hypsizygus tessulatus & $46.9 \pm 18.3$ \\
Pleurotus eryngii & $78.2 \pm 28.7$ \\
Pleurotus florida & $68.6 \pm 23.9$ \\
Auricularia polytricha & $115.8 \pm 16.1$ \\
Flammulina velutipes & $100.1 \pm 9.8$ \\
Potassium dichromate & $17.0 \pm 2.9$ \\
\hline
\end{tabular}

Note: $L C_{50}$, concentration required to kill $50 \%$ of a group of shrimps; values reported as mean $\pm S E(n=3)$

\section{DISCUSSION}

In this paper, a total of five edible mushrooms commonly used in Malaysia were selected for study. The five samples represent members of four mushroom families, namely Lyophyllaceae $(H$. tessulatus), Pleurotaceae ( $P$. eryngii, $P$. florida), Auriculariaceae (A. polytricha) and Physalacriaceae ( $F$. velutipes). These five mushrooms are frequently used and incorporated in local diets in a variety of forms. The fruiting bodies of the mushrooms were used in this study to reflect their actual usage by the local people. Additionally, a previous report has indicated that more than $80 \%$ of all mushrooms bioactive metabolites were extracted from the fruiting bodies, while only about $15 \%$ of all identified compounds were extracted from the mycelia [7].

As radical scavenging activity is frequently linked to chemoprevention potential [16], we first tested these selected mushrooms for their scavenging activities. Similar positive correlation between mushroom phenolic contents and their corresponding antioxidation properties had previously been reported in other mushrooms species [17].

Additionally, we also tested the five mushroom species for their metal chelating activities, as the antioxidant properties of phenolic compounds may also be mediated by their ability to chelate trace metals involved in free radical formation. With the exception of $P$. eryngii, high metal chelating activities (> $90 \%$ ) were observed with all mushroom extracts, tested at a concentration of $50 \mathrm{mg} / \mathrm{ml}$. However, no strong correlation was observed between metal chelating activities and total phenolic $\left(R^{2}=0.16, p<0.05\right)$ or flavonoid content $\left(R^{2}=0.13, p<0.05\right)$. For instance, lowest levels of phenolic and flavonoid were detected in $F$. velutipes, yet this mushroom species exhibited the second highest metal chelating activities, among the five mushroom species tested. In contrast, despite the moderate total phenolic and flavonoid contents detected in $P$. eryngii, it demonstrated the lowest metal chelating activity.

Previously, studies conducted using medicinal herbs and mushrooms indicated very poor or no positive correlation between metal chelating activities and total phenolic or flavonoid content [18]. It was reported that phenolics' metal chelating power is determined by their chemical structures and the availability of properly oriented functional groups, with six-membered ring complexes exhibited stronger chelating potential than five-membered ring structures [19]. Additionally, the study showed the significant contribution from catechol moiety toward metal-chelating activity [20]. Proteins and polysaccharides had also been implicated in metal-chelating activities [18]. These aforementioned studies may help to explain why high metal-chelating activity was found for $F$. velutipes, despite its low phenolic and flavonoid contents.

The mushroom extracts were also tested for their antibacterial activities against four bacteria strains. In order to reflect their true potential as functional food, water was chosen as the extraction solvent. In the disk-diffusion test, we found that $P$. florida selectively exhibited moderate inhibition activities against both Gramnegative bacterial strains tested. Future work with other Gram-negative bacterial strains may help to determine whether $P$. florida exerts its inhibition activity in a Gram-specific manner. Lastly, brine shrimp cytotoxic assay indicated that the five selected mushroom extracts had lower cytotoxicity than the potassium dichromate control. Among the mushrooms tested, $A$. polytricha exhibited the lowest cytotoxicity, about 7 -fold lower than control. Low cytotoxicity suggests that these mushrooms species can be safely consumed in large quantities.

\section{CONCLUSION}

We reported here the radical scavenging activities of five edible mushrooms used by the local population in Malaysia. Among the mushrooms tested, A. polytricha demonstrated the strongest radical scavenging and metal chelating activities, as well as the highest 
polyphenolic and flavonoid contents. Additionally, $A$. polytricha exhibited the lowest cytotoxicity. These findings suggest that $A$. polytricha is a suitable candidate for use in chemoprevention and is safe for consumption in large quantities. Further work could potentially lead to the isolation of powerful antioxidants with low cytotoxicity and high safe profiles.

\section{ACKNOWLEDGMENT}

This research was supported by Toray Science Foundation (Japan) and UTAR Research Fund (UTARRF), Malaysia.

\section{REFERENCES}

1. Barros L, Cruz T, Baptista P, Estevinho L, Ferreira I. Wild and commercial mushrooms as source of nutrients and nutraceuticals. Food Chem. Toxicol. 2008; 46: 2742-2747.

2. Gursoy N, Sarikurkcu C, Tepe B, Solak HM. Evaluation of antioxidant activities of 3 edible mushrooms: Ramaria flava (Schaef.: Fr.) Quel., Rhizopogon roseolus (Corda) T.M. Fries., and Russula delica Fr. . Food Science and Biotechnology Food Sci. Biotechnol. 2010; 19(3): 691-696.

3. Lam $Y, N g T$, Wang $H$. Antiproliferative and antimitogenic activities in a peptide from puffball mushroom Calvatia caelata. Biochem. Biophys. Res. Commun. 2001; 289: 744-749.

4. Kodama N, Komuta K, Nanba H. Effect of maitake (Grifola frondosa) $D$-fraction on the activation of NK cells in cancer patients. J. Med. Food 2003; 6(4): 371-377.

5. Gao Y, Zhou S, Jiang W, Huang M, Dai X. Effects of Ganopoly® (a Ganoderma lucidum polysaccharide extract) on the immune functions in advancedstage cancer patients. Immunol. Investig. 2003; 32(3): 201-215.

6. Mitomi $T$, Tsuchiya $S$, lijima $N$, Aso $K$, Suzuki $K$, Nishiyama K, Amano T, Takahashi T, Murayama $N$, Oka $H$, et al. Randomized, controlled study on adjuvant immunochemotherapy with $P S K \circledast$ in curatively resected colorectal cancer. Dis. Colon Rectum 1992; 35(2): 123-130.

7. Lindequist $U$, Niedermeyer THJ, Julich $W$-D. The pharmacological potential of mushrooms. eCAM 2005; 2(3): 285-299.
8. Mothana $R$, Awadh $N$, Julich $W$, Lindequist $U$. Ganomycin $A$ and $B$, new antimicrobial farnesyl hydroquinones from the basidiomycete Ganoderma pfeifferi. J. Nat. Prod. 2000; 63: 416418.

9. Hall IR, Buchanan PK, Stephenson SL, Yun W, Cole ALJ (2010) Edible and Poisonous Mushrooms of the World; Timber Press Portland, OR, USA.

10. Chang ST, Miles PG (2004) Mushrooms : cultivation, nutritional value, medicinal effect, and environmental impact (2nd edn.), CRC Press, Boca Raton, FL, USA

11. Wong FC, Chai TT, Hoo YW. Antioxidation and cytotoxic activities of selected medicinal herbs used in Malaysia. J. Med. Plant Res. 2012; 6(16): 3169-3175.

12. Chew Y-L, Goh J-K, Lim Y-Y. Assessment of in vitro antioxidant capacity and polyphenolic composition of selected medicinal herbs from Leguminosae family in Peninsular Malaysia. Food Chem. 2009; 116(1): 13-18.

13. Ainsworth EA, Gillespie KM. Estimation of total phenolic content and other oxidation substrates in plant tissues using Folin-Ciocalteu reagent. Nature Protocols 2007; 2(4): 875-877.

14. Chai TT, Wong FC. Antioxidant properties of aqueous extracts of Selaginella willdenowii. J. Med. Plant Res. 2012; 6(7): 1289-1296.

15. McLaughlin JL, Rogers LL. The use of biological assays to evaluate botanicals. Drug Inf. J. 1998; 32: 513524.

16. Wong JY, Chye FY. Antioxidant properties of selected tropical wild edible mushrooms. J. Food Compos. Anal. 2009; 22(4): 269-277.

17. Rathee S, Rathee D, Kumar V, Rathee P. Mushrooms as therapeutic agents. Braz. J. Pharmacog. 2012 22(2): 459-474.

18. Rainha N, Lima E, PBaptista J, Rodrigues C. Antioxidant properties, total phenolic, total carotenoid and chlorophyll content of anatomical parts of Hypericum foliosum. J. Med. Plant Res. 2011; 5(10): 1930-1940.

19. Thompson M, Williams CR. Stability of flavonoid complexes of copper (II) and flavonoid antioxidant activity. Anal. Chim. Acta 1976; 85: 375-381.

20. Sestili $P$, Diamantini G, Bedini A, Cerioni A, Tommasini I, Tarzia G, Cantoni O. Plant-derived phenolic compounds prevent the DNA single-strand breakage and cytotoxicity induced by tertbutylhydroperoxide via an iron-chelating mechanism. Biochem. J. 2002; 364: 121-128. 